\title{
EFEKTIVITAS MODEL BENEISH M-SCORE DAN MODEL F-SCORE DALAM MENDETEKSI KECURANGAN LAPORAN KEUANGAN
}

\author{
Jason Hugo \\ Fakultas Ekonomi, Universitas Tarumanegara Jakarta \\ Email: Jason_Hugo@outlook.com
}

Masuk : 13-08-2019, revisi: 17-08-2019, diterima untuk diterbitkan : 17-08-2019

\begin{abstract}
ABSTRAK
Penelitian ini menguji efektivitas model Beneish M-Score dan model F-Score dalam mendeteksi kecurangan laporan keuangan. Seturut dengan peningkatan skandal kecurangan, pemangku kepentingan memerlukan model deteksi yang dapat diandalkan sehingga mengurangi asimetri informasi dan kerugian. Model Beneish M-Score dan model F-Score diuji secara empiris untuk mengevaluasi hubungan dan signifikansi kedua model dengan kecurangan laporan keuangan. Hipotesis dalam penelitian ini antara lain: model Beneish M-Score dan model F-Score secara parsial efektif dalam mendeteksi kecurangan laporan keuangan, dan variabel-variabel dalam model Beneish M-Score dan model F-Score secara parsial dan simultan memiliki hubungan positif dengan kecurangan laporan keuangan. Menggunakan metode partial least squares structural equation modelling, hipotesis diuji menggunakan data emiten yang terdaftar di bursa efek Amerika Serikat. Hasil pengujian menunjukkan bahwa kedua model terbukti efektif dan memiliki korelasi positif yang kuat terhadap kecurangan laporan keuangan.
\end{abstract}

Kata Kunci : Beneish M-Score, F-Score, Kecurangan Laporan Keuangan, Asimteri Informasi.

ABSTRACT

This research investigates the effectiveness of Beneish M-Score and F-Score models in detecting fraudulent of financial statements. In the rise of financial statement frauds cases, stakeholders require reliable detection model to minimize information asymmetry and damages. These models were empirically tested to evaluate the correlation and significance of both models with the fraudulent of financial statements. The hypotheses of this research were: Beneish M-Score and F-Score models were partially effective in detecting the fraudulent of financial statements, and the variables of the Beneish $M$ and the F-Score models were partially and simultaneously correlated with the fraudulent of financial statements. With the partial least squares structural equation modelling, the hypotheses were tested using data from public companies which were listed in the United States' Stock Exchange. The outcome of this test shows that both models are partially effective and correlated positively with the fraudulent of financial statements.

Keywords : Beneish M-Score, F-Score, Fraudulent of Financial Statements, Information Asymmetry.

\section{PENDAHULUAN}

\section{Konteks Penelitian}

Selama dua dekade terakhir, kasus - kasus kecurangan laporan keuangan, seperti Enron Corporation (Bloomberg, 2001), Satyam Computer Services (Balachandran, 2009), Worldcom (Tran, 2002), Waskita Karya (Detik Finance, 2009), dan Toshiba (Alpeyev dan Amano, 2015), menimbulkan kerugian besar. Meresponi hal ini, ACFE (2016) menominasikan kecurangan laporan keuangan sebagai jenis kecurangan yang bersifat paling destruktif. Secara teori , kecurangan laporan keuangan ditimbulkan karena konflik kepentingan antara agent dan principal (Jensen dan Meckling, 1976), sehingga menimbulkan agency cost dan monitoring cost (Hery, 2016). Agency cost adalah biaya yang dikeluarkan, berupa gaji besar, bonus, dan saham, oleh pemegang saham untuk menekan keinginan manajemen untuk melakukan kecurangan (Jensen dan Meckling, 2016). Sedangkan monitoring cost merupakan biaya audit untuk memeriksa laporan keuangan yang disajikan oleh manajemen dan memberi suatu tingkat keyakinan bahwa laporan keuangan bebas dari salah saji material (Hery, 2016). Meskipun demikian, survei ACFE (2016) menunjukkan bahwa persentase keberhasilan audit eksternal dalam mendeteksi kecurangan laporan keuangan hanya sebesar 3,8 persen. Selain itu, auditor 
kerap terlibat secara langsung dalam skema kecurangan, seperti dalam kasus PT. Waskita Karya, dimana auditor tidak mengoreksi penggelembungan pendapatan sebesar Rp. 5 Miliar dan tetap memberikan opini wajar tanpa pengecualian (Rahadiana, 2009).

Dengan demikian, pemangku kepentingan (stakeholders) perlu dibekali instrumen deteksi yang dapat mengevaluasi kelayakan sebuah laporan keuangan sehingga dapat digunakan sebagai dasar pengambilan keputusan. Dua di antaranya adalah model Beneish M-Score dan model F-Score. Model Beneish M-Score merupakan model prediksi kecurangan laporan keuangan - manajemen laba, dimana rasio-rasio yang terkandung di dalamnya telah terbukti memiliki kemampuan memprediksi kecurangan laporan keuangan (Beneish, 1999). Semakin besar nilai M Beneish suatu laporan keuangan, dengan nilai cut-off sebesar -2,22, maka semakin besar kemungkinan laporan keuangan mengandung kecurangan (Tarjo dan Herawati, 2015; Cecchini et al., 2010; Aris et al., 2015; dan Repousis, 2016). Namun penelitian Bhavani dan Amponsah (2017) membuktikan bahwa model gagal dalam mendeteksi kecurangan yang dilakukan oleh Toshiba. Oleh karena itu relevansi model Beneish $M$-Score di era modern perlu diuji kembali. Model $F$ Score juga merupakan model prediksi kecurangan laporan keuangan (Dechow et al., 2011). Model dikembangkan dengan memanfaatkan data dari periode 1982 - 2005 sehingga relevansi dan reliabilitas model $F$-Score masih perlu diuji, khususnya dengan menggunakan sampel data terbaru, sebab standar akuntansi Generally Accepted Accounting Principles telah banyak mengalami perubahan sejak krisis moneter 2008.

Penelitian ini berfokus pada pengujian efektivitas model Beneish $M$-Score dan model $F$-Score dalam mendeteksi kecurangan laporan keuangan dengan menghitung nilai $\mathrm{M}$ Beneish dan nilai $\mathrm{F}$ dari masing-masing laporan keuangan. Selain itu, variabel-variabel yang terkandung dalam model Beneish M-Score dan model F-Score dengan kecurangan laporan keuangan juga diuji, baik secara parsial dan simultan.

\section{Kajian Teori}

Agency Theory. Teori keagenan menjelaskan konflik kepentingan antara agent dan principal (Jensen dan Meckling, 1976). Di satu sisi, manajemen dituntut untuk mengambil keputusan strategis yang memaksimalkan pengembalian investasi, berupa pembayaran dividen dan capital gain. Di sisi lain manajemen juga memiliki misi untuk memperkaya diri sendiri (Scott, 2015). Konsekuensinya manajemen kerap menciptakan situasi dan kondisi, salah satunya dengan manipulasi laporan keuangan, agar insentif bonus dapat dimaksimalkan. Konflik kepentingan menimbulkan agency cost dan monitoring cost. Agency cost adalah biaya yang dikeluarkan, berupa gaji besar, bonus, dan saham, oleh pemegang saham untuk menekan keinginan manajemen untuk melakukan kecurangan (Jensen dan Meckling, 1976). Sedangkan monitoring cost adalah biaya audit untuk memeriksa laporan keuangan yang disajikan oleh manajemen, apakah telah bebas dari salah saji material dan disajikan sesuai dengan standar akuntansi yang berlaku (Hery, 2016).

Signalling Theory. Teori sinyal menjelaskan asimetri informasi, berupa kualitas dan kuantitas data, antara pihak internal dan eksternal perusahaan (Spence, 1973). Kesenjangan informasi menimbulkan ketidakpastian, sehingga dapat memperburuk citra (image) perusahaan. Oleh karena itu, data dan informasi bersifat material perlu dipublikasikan sebagai sinyal terkait performa perusahaan selama periode tertentu Higson, 2003). Sinyal lainnya dapat berupa tingkat keyakinan auditor atas suatu laporan keuangan, yang dikemukakan dalam bentuk opini audit (Hery, 2016), dan berupa red flag dari hasil perhitungan nilai M Beneish (Beneish, 1999) dan nilai $\mathrm{F}$ (Dechow et al., 2011). 
Fraud Diamond Theory. Wolfe dan Hermanson (2004) menjabarkan bahwa unsur pressure, opportunity, rationalization, dan capability merupakan motivator perbuatan curang. Pressure merupakan tekanan, seperti tekanan bisnis, politik, target perusahaan, manajer, yang memaksa manajer untuk melakukan window dressing sehingga laporan keuangan dapat terlihat memuaskan. Opportunity merupakan suatu kesempatan, dapat dikarenakan sistem pengendalian internal yang lemah untuk melakukan kecurangan tanpa terdeteksi. Rationalization merupakan pikiran, pandangan, perspektif, atau kepercayaan seseorang dalam membenarkan tindakan tidak beretika. Capability merupakan kompetensi dan pengetahuan seseorang untuk mengeksekusi kecurangan dengan berhasil.

Beneish M-Score. Model ini merupakan model untuk memprediksi kecurangan laporan keuangan - manajemen laba yang dikembangkan dengan menggunakan logit regression, dimana delapan rasio keuangan yang terkandung dalam model ditentukan dan diuji dengan menggunakan principle component analysis (Beneish, 1999). Delapan rasio yang terkandung dalam model, antara lain days sales receivable index (DSRI), gross margin index (GMI), depreciation index (DEPI), sales growth index (SGI), leverage index (LVGI), total accruals to total assets (TATA), asset quality index (AQI), dan sales general administrative index (SGAI). Laporan keuangan dengan nilai $\mathrm{M}$ Beneish lebih besar dari -2,22 patut diduga mengandung kecurangan (Tarjo dan Herawati, 2015). Beneish (1999) juga menyatakan bahwa seluruh variabel memiliki hubungan positif signifikan dengan kecurangan laporan keuangan.

F-Score. Model ini merupakan model deteksi kecurangan laporan keuangan yang dikembangkan dengan menggunakan teknik scaled logistic probability (Dechow et al., 2011). Model F-Score merupakan pengembangan model Beneish M-Score yang didesain secara khusus agar pengguna mampu mendapatkan nilai (score) secara langsung tanpa menggunakan indeks dalam perhitungannya. Terdapat tujuh rasio yang terkandung dalam model F-Score, antara lain RSST accruals, changes in receivables, changes in inventories, percentages of soft assets, changes in cash sales, changes in return on assets, dan issuance, dimana laporan keuangan dengan nilai $\mathrm{F}$ lebih besar dari satu patut diduga mengandung kecurangan. Variabel changes in cash sales memiliki hubungan negatif signifikan, dan variabel lainnya memiliki hubungan positif nan signifikan dengan kecurangan laporan keuangan (Dechow et al., 2011).

Kecurangan Laporan Keuangan. Adalah tindakan ilegal manajemen untuk menipu pengguna laporan keuangan dengan cara menyembunyikan atau mengubah informasi bersifat material, dengan tujuan untuk kepentingan pribadi atau pihak tertentu (Tuanakotta, 2013). Terdapat beberapa red flags, suatu indikasi bahwa terdapat kejanggalan, dalam konteks akuntansi pada akun-akun tertentu, sehingga membutuhkan perhatian khusus, pada laporan keuangan yang mengandung kecurangan (Singleton dan Singleton, 2010).

Kerangka Pemikiran dalam penelitian ini dapat digambarkan sebagai berikut: 


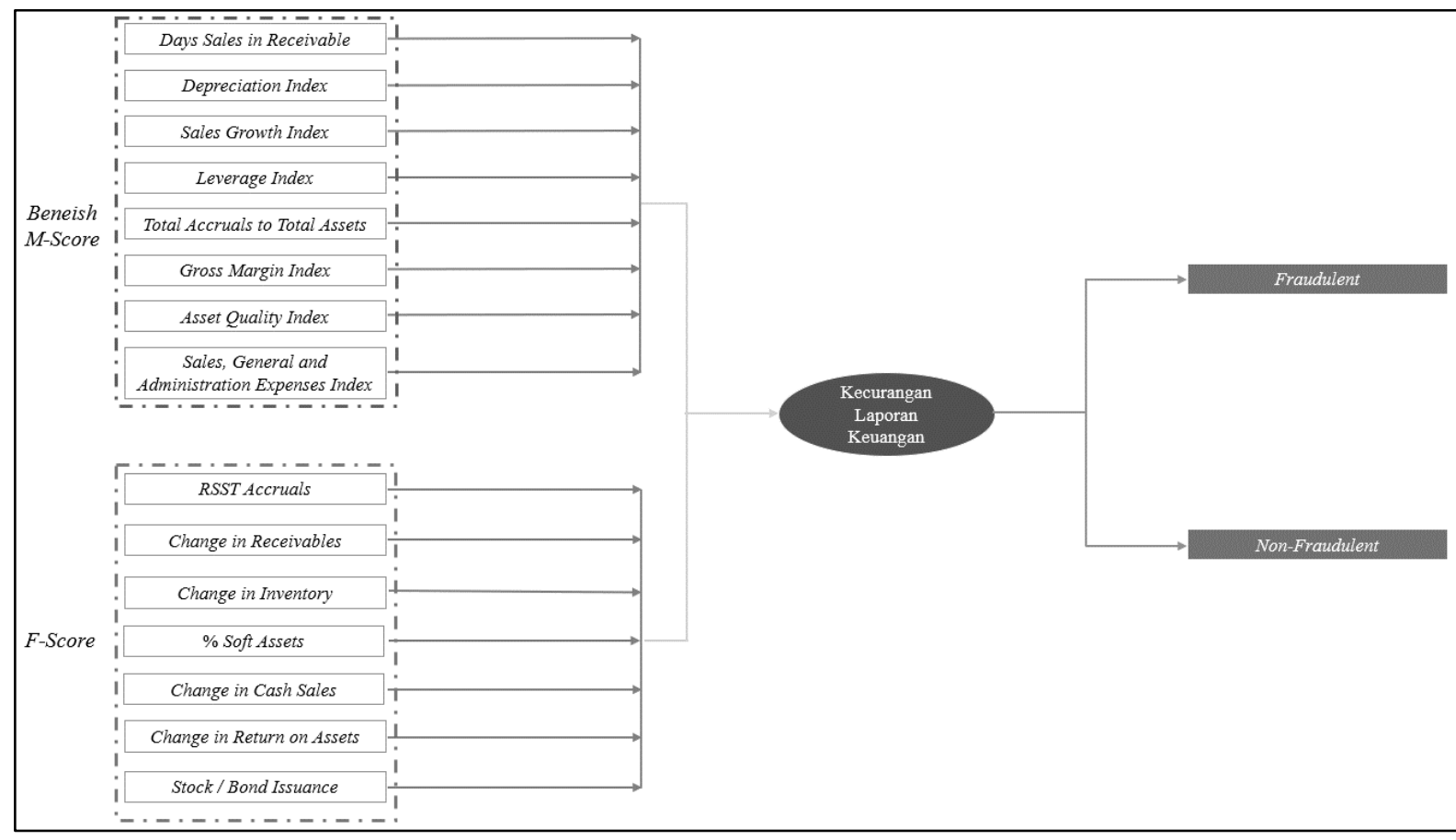

Hipotesis yang dibangun dari model di atas adalah, sebagai berikut:

$\mathrm{H}_{1}$ : Variabel-variabel dalam Beneish $M$-Score secara simultan berhubungan positif signifikan dengan kecurangan laporan keuangan

$\mathrm{H}_{1.1}$ : Days sales receivable index berhubungan positif signifikan dengan kecurangan laporan keuangan

$\mathrm{H}_{1.2}$ : Gross margin index berhubungan positif signifikan dengan kecurangan laporan keuangan

$\mathrm{H}_{1.3}$ : Depreciation index berhubungan positif signifikan dengan kecurangan laporan keuangan

$\mathrm{H}_{1.4}$ : Sales growth index berhubungan positif signifikan dengan kecurangan laporan keuangan

$\mathrm{H}_{1.5}$ : Leverage Index berhubungan positif signifikan dengan kecurangan laporan keuangan

$\mathrm{H}_{1.6}$ : Total accruals to total assets berhubungan positif signifikan dengan kecurangan laporan keuangan

$\mathrm{H}_{1.7}$ : Asset Quality Index berhubungan positif signifikan dengan kecurangan laporan keuangan

$\mathrm{H}_{1.8}$ : Sales, general, and administrative index berhubungan positif signifikan dengan kecurangan laporan keuangan

$\mathrm{H}_{2}$ : Variabel-variabel dalam $F$-Score secara simultan berhubungan positif signifikan dengan kecurangan laporan keuangan

$\mathrm{H}_{2.1}$ : RSST accruals berhubungan positif signifikan dengan kecurangan laporan keuangan

$\mathrm{H}_{2.2}$ : Changes in receivables berhubungan positif signifikan dengan kecurangan laporan keuangan

$\mathrm{H}_{2.3}$ : Changes in inventories berhubungan positif signifikan dengan kecurangan laporan keuangan

$\mathrm{H}_{2.4}$ : Percentages of soft assets berhubungan positif signifikan dengan kecurangan laporan keuangan

$\mathrm{H}_{2.5}$ : Changes in cash sales berhubungan negatif signifikan dengan kecurangan laporan keuangan 
$\mathrm{H}_{2.6}$ : Changes in return on assets berhubungan positif signifikan dengan kecurangan laporan keuangan

$\mathrm{H}_{2.7}$ : Issuance berhubungan positif signifikan dengan kecurangan laporan keuangan

$\mathrm{H}_{3}$ : Model Beneish M-Score efektif dalam mendeteksi kecurangan laporan keuangan

$\mathrm{H}_{4}$ : Model $F$-Score efektif dalam mendeteksi kecurangan laporan keuangan

\section{METODE PENELITIAN}

\section{Metodologi}

Penelitian ini dilakukan atas emiten Amerika serikat yang melakukan kecurangan laporan keuangan pada tahun 1997 - 2017. Daftar emiten yang melakukan kecurangan dan laporan keuangan diperoleh dari Accounting and Auditing Enforcement Releases dan EDGAR Database. Kedua sumber tersebut dapat diakses pada situs www.sec.gov. Pemilihan sampel dilakukan dengan purposive sampling method dengan kriteria : (1) Terbukti melakukan kecurangan laporan keuangan; (2) Mempublikasikan laporan keuangan teraudit berturut-turut sebelum, selama, dan sesudah periode kecurangan; (3) Terdaftar di bursa efek selama lebih dari 10 tahun; dan (4) Mengandung seluruh data yang diperlukan dalam perhitungan model Beneish $M$-Score dan FScore. Sampel kemudian diseleksi kembali dengan menggunakan metode stratified random sampling. Dari 494 jumlah populasi, terpilih 100 sampel yang terdiri dari 64 perusahaan manufaktur, 11 perusahaan konstruksi, 11 perusahaan real estate, 6 perusahaan tambang, dan 5 perusahaan kimia.

Variabel operasional dalam penelitian ini terdiri dari Beneish M-Score, F-Score, dan kecurangan laporan keuangan. Variabel yang terkandung dalam model Beneish M-Score terdiri dari days sales receivable index (DSRI), gross margin index (GMI), depreciation index (DEPI), sales growth index (SGI), leverage index (LVGI), total accruals to total assets (TATA), asset quality index (AQI), dan sales general administrative index (SGAI), dengan rumus:

$$
\begin{aligned}
& \text { DSRI }=\frac{\text { Receivables }_{t} / \text { Sales }_{t}}{\text { Net Receivables } t-1_{t} / \text { Sales }_{t-1}} ; \\
& \text { LVGI }=\frac{\left(\mathrm{CL}_{\mathrm{t}}+\mathrm{LTD}_{\mathrm{t}}\right) / \mathrm{TA}_{\mathrm{t}}}{\left(\mathrm{CL}_{\mathrm{t}-1}+\mathrm{LTD}_{\mathrm{t}-1}\right) / \mathrm{TA}_{\mathrm{t}-1}} ; \\
& \text { GMI }=\frac{\left(\text { Sales }_{t-1}-\text { COGS }_{t-1}\right) / \text { Sales }_{t-1}}{\left(\text { Sales }_{t}-\text { COGS }_{t}\right) / \text { Sales }_{t}} ; \\
& \mathrm{AQI}=\frac{1-\left[\left(\mathrm{CA}_{t}+\mathrm{PP} \& \mathrm{E}_{\mathrm{t}}+\text { Securities }_{\mathrm{t}}\right) / \mathrm{TA}_{t}\right]}{1-\left[\left(\mathrm{CA}_{\mathrm{t}-1}+\operatorname{PP} \& \mathrm{E}_{\mathrm{t}-1}+\text { Securities }_{\mathrm{t}-1}\right) / \mathrm{TA}_{\mathrm{t}-1}\right]} ; \\
& \text { DEPI }=\frac{\text { Depreciation }_{t-1} /\left(\text { PP\&E }_{t-1}+\text { Depreciation }_{t-1}\right)}{\text { Depreciation }_{t} /\left(\text { PP\&E }_{t}+\text { Depreciation }_{t}\right)} \text {; } \\
& \text { SGAI }=\frac{\text { SG\&A Expense }_{t} / \text { Sales }_{t}}{\text { SG\&A Expense }_{t-1} / \text { Sales }_{t-1}} \text {; } \\
& \mathrm{SGI}=\frac{\text { Sales } \mathrm{t}}{\text { Sales }_{\mathrm{t}-1}} \text {; }
\end{aligned}
$$

Nilai M Beneish dapat dihitung dengan menggunakan rumus berikut:

$$
\begin{aligned}
\mathrm{M}= & -4,840+0,920 \mathrm{DSRI}+0,528 \mathrm{GMI}+0,404 \mathrm{AQI}+0,892 \mathrm{SGI}+0,115 \mathrm{DEPI}- \\
& 0,172 \mathrm{SGAI}+4,679 \text { TATA }-0,327 \mathrm{LVGI}
\end{aligned}
$$

Sedangkan variabel yang terkandung dalam model F-Score adalah RSST accruals, changes in receivables, changes in inventories, percentages of soft assets, changes in cash sales, changes in return on assets, dan issuance, yang dapat dirumuskan sebagai:
RSST_ACC $=\frac{\Delta W C+\triangle N C O+\triangle F I N}{\text { Average Total Assets }}$;
Ch_CS $=\frac{\text { Sales }_{t}-\Delta \text { Accounts Receivable }_{t}}{\text { Sales }_{t-1}-\Delta \text { Accounts Receivable }_{t-1}}$;
Ch_Rec $=\frac{\Delta \text { Accounts Receivable }}{\text { Average } \text { Total Assets }}$;
Ch_ROA $=\frac{\text { Earnings }_{t} / \text { Average } \text { Total Assets }_{t}}{\text { Earnings }_{t-1} / \text { Average } \text { Total Assets }_{t-1}}$; 


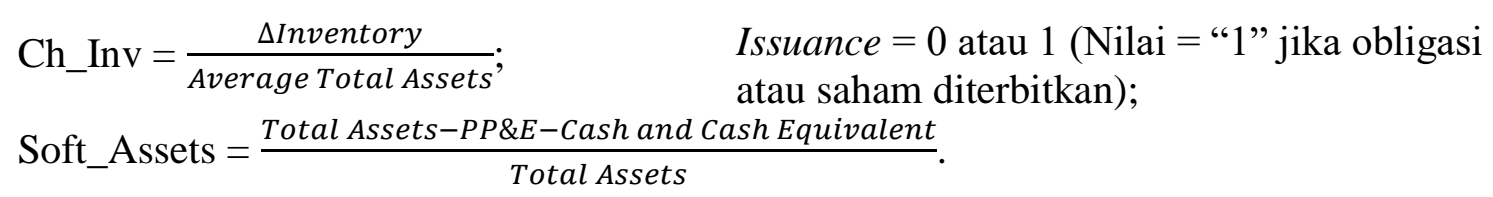

Nilai F dapat dihitung dengan menggunakan rumus berikut:

$$
\begin{array}{ll}
\text { F-Score }=\frac{e^{(\text {Predicting Value })}}{\left(1+e^{(\text {Predicted Value })}\right)} \div \frac{\text { Number of Misstatement Firms }}{\text { Total Number of Firms }} \\
\text { Predicted }= & -7,893+0,790(\text { RSST_Acc })+2,518(\text { ch_rec })+1,191(\mathrm{ch} \text { inv })+ \\
\text { Value } & \begin{array}{l}
1,979(\text { soft_assets })+0,171(\text { ch_cs })+(-0,932)(\text { ch_ROA })+1,029 \\
\text { (issue })
\end{array}
\end{array}
$$

Memanfaatkan pendekatan partial least squares - structural equation modelling, pengujian dilakukan dengan mengevaluasi pada model pengukuran (outer model) dan model struktural (inner model) (Ghozali dan Latan, 2015). Evaluasi pada model pengukuran berupa pengujian weight significant dan multikolinieritas. Pada model struktural terdiri dari : (1) Pengujian the goodness of fit (R-Square); (2) Pengujian efek variabel bebas terhadap variabel terikat ( $F$ Square); (3) Pengujian predictive relevance ( $Q$-Square); dan (4) pengujian hipotesis ( $P$-Value).

\section{HASIL DAN PEMBAHASAN Hasil Uji Statistik}

Hasil statistik deskriptif untuk periode 1997 - 2017 menunjukkan bahwa Days Sales in Receivables Index memiliki nilai mean sebesar 1,130 , nilai minimum sebesar 0,856 , nilai maximum sebesar 1,348, dan nilai standar deviasi sebesar 0,127. Gross Margin Index memiliki nilai mean sebesar 1,067, nilai minimum sebesar 0,564 , nilai maximum sebesar 1,330 , dan nilai standar deviasi sebesar 0,180. Depreciation Index memiliki nilai mean sebesar 1,028, nilai minimum sebesar 0,913, nilai maximum sebesar 1,157 , dan nilai standar deviasi sebesar 0,057 . Sales Growth Index memiliki nilai mean sebesar 1,322, nilai minimum sebesar 1,045, nilai maximum sebesar 1,955, dan nilai standar deviasi sebesar 0,292. Leverage Index memiliki nilai mean sebesar 1,021 , nilai minimum sebesar 0,812 , nilai maximum sebesar 1,394 , dan nilai standar deviasi sebesar 0,144. Total Accruals to Total Assets memiliki nilai mean sebesar 0,087, nilai minimum sebesar 0,049, nilai maximum sebesar 0,192, dan nilai standar deviasi sebesar 0,028. Asset Quality Index memiliki nilai mean sebesar 1,074, nilai minimum sebesar 0,653, nilai maximum sebesar 1,655, dan nilai standar deviasi sebesar 0,193. Sales, General, and Administrative Expenses memiliki nilai mean sebesar 1,033, nilai minimum sebesar 0,823, nilai maximum sebesar 1,345, dan nilai standar deviasi sebesar 0,118. RSST Accruals memiliki nilai mean sebesar 0,097, nilai minimum sebesar 0,014, nilai maximum sebesar 0,263, dan nilai standar deviasi sebesar 0,067. Changes in Receivables memiliki nilai mean sebesar 0,024, nilai minimum sebesar 0,002, nilai maximum sebesar 0,095, dan nilai standar deviasi sebesar 0,023. Changes in Inventory memiliki nilai mean sebesar 0,043, nilai minimum sebesar 0,010, nilai maximum sebesar 0,212, dan nilai standar deviasi sebesar 0,034. Percentages of Soft Assets memiliki nilai mean sebesar 0,651, nilai minimum sebesar 0,515 , nilai maximum sebesar 0,792 , dan nilai standar deviasi sebesar 0,062. Changes in Cash Sales memiliki nilai mean sebesar 0,301 , nilai minimum sebesar 0,105 , nilai maximum sebesar 0,825 , dan nilai standar deviasi sebesar 0,187. Changes in Return on Assets memiliki nilai mean sebesar 0,046, nilai minimum sebesar 0,011, nilai maximum sebesar 0,213, dan nilai standar deviasi sebesar 0,031. Issuance of Shares or Obligations memiliki nilai mean sebesar 0,640, nilai minimum sebesar 0,000, nilai maximum sebesar 1,000, dan nilai standar deviasi sebesar 0,594. 
Pengujian model pengukuran (outer model). Validitas ditentukan dengan menghitung signifikansi beban variabel eksogen terhadap variabel endogen (Ghozali dan Latan, 2015). Mengacu pada Tabel 1, seluruh variabel eksogen, dengan pengecualian depreciation index, sales, general, and administrative index, dan changes in return on assets, memiliki beban signifikan dengan nilai $\mathrm{T}$ lebih besar dari 1,96. Variabel-variabel yang tidak memiliki beban signifikan tidak dikeluarkan dari obyek penelitian sebab seluruh variabel akan diuji secara bersamaan sebagai satu kesatuan dari model. Variabel eksogen juga telah memenuhi uji multikolinearitas sebab memiliki nilai variance inflation factor lebih kecil dari 5 (Tabel 2).

Pengujian model struktural (inner model). Nilai $R$-Square sebesar 0,961 menunjukkan bahwa 96,1 persen variabel endogen kecurangan laporan keuangan dapat dijelaskan oleh variabelvariabel eksogen dalam penelitian ini, sedangkan 3,9 persen lainnya dapat dijelaskan oleh variabel di luar penelitian. Dengan demikian dapat disimpulkan bahwa model penelitian ini adalah kuat. Lalu perhitungan $F$-Square juga menunjukkan bahwa Beneish $M$-Score dan $F$-Score dengan nilai $F$-Square sebesar 0,833 dan 0,865 memiliki efek yang besar terhadap kecurangan laporan keuangan. Dan dengan nilai $Q$-Square sebesar 0,911, dapat disimpulkan bahwa model penelitian ini memiliki predictive relevance.

Tabel 1

Weight Significance, T-Value, P-Value

\begin{tabular}{lcccccc}
\hline \multirow{2}{*}{ Variabel } & \multicolumn{3}{c}{ Beneish M-Score } & \multicolumn{3}{c}{ F-Score } \\
\cline { 2 - 7 } DSRI & Weight & $T$ & $P$ & Weight & $T$ & $P$ \\
\hline GMI & 0,207 & 5,327 & 0,000 & & & \\
\hline DEPI & 0,401 & 7,362 & 0,000 & & & \\
\hline SGI & 0,094 & 1,873 & 0,061 & & & \\
\hline LVGI & 0,165 & 4,203 & 0,000 & & & \\
\hline TATA & 0,149 & 3,114 & 0,002 & & & \\
\hline AQI & 0,132 & 4,268 & 0,000 & & & \\
\hline SGAI & 0,131 & 2,785 & 0,005 & & & \\
\hline RSST Accruals & 0,048 & 1,776 & 0,076 & & & \\
\hline Ch_Rec & & & 0,301 & 4,764 & 0,000 \\
\hline Ch_Inv & & & 0,260 & 3,854 & 0,000 \\
\hline Soft Assets & \multicolumn{7}{c}{0,230} & 5,150 & 0,000 \\
\hline Ch_CS & \multicolumn{7}{c}{0,357} & 4,236 & 0,000 \\
\hline Ch_ROA & & & $-0,190$ & 3,305 & 0,001 \\
\hline Issuance & & & 0,017 & 0,194 & 0,849 \\
\hline Simultan & 0,494 & 7,442 & 0,000 & 0,504 & 7,543 & 0,000 \\
\hline
\end{tabular}

Uji T-Statistik. Pengujian ini digunakan untuk menguji keterkaitan antara variabel bebas dengan variabel terikat. Seluruh variabel yang terkandung dalam model Beneish M-Score dan model FScore, dengan pengecualian depreciation, index, sales, general, and administrative index, dan changes in return on assets, memiliki p-value lebih kecil dari 0,05. Dengan demikian dapat disimpulkan bahwa variabel-variabel ini memiliki hubungan yang signifikan dengan kecurangan laporan keuangan, dimana variabel days sales receivable index $(0,207)$, gross margin index $(0,401)$, sales growth index $(0,165)$, leverage index $(0,149)$, total accruals to total assets $(0,132)$, asset quality index $(0,131)$, RSST accruals $(0,301)$, changes in receivables $(0,260)$, changes in inventories $(0,230)$, percentages of soft assets $(0,357)$, dan issuance $(0,250)$ memiliki hubungan 
positif, sedangkan changes in cash sales $(-0,190)$ memiliki hubungan negatif dengan kecurangan laporan keuangan. Seluruh hipotesis, dengan pengecualian $\mathrm{H}_{1.3}, \mathrm{H}_{1.8}$, dan $\mathrm{H}_{2.6}$, dapat diterima.

Sedangkan hasil pengujian efektivitas model Beneish M-Score dan model F-Score dalam mendeteksi kecurangan laporan keuangan dapat dilihat pada Tabel 3. Dalam pengujian ini, terbukti bahwa model Beneish M-Score mampu mengidentifikasikan laporan keuangan yang mengandung kecurangan secara akurat. Namun model ini salah dalam mengidentifikasikan empat belas laporan keuangan non-fraudulent sebagai fraudulent, dimana memiliki nilai $\mathrm{M}$ Beneish lebih besar dari -2,22. Secara keseluruhan model Beneish M-Score memiliki tingkat akurasi sebesar delapan puluh enam persen.

Sedangkan model F-Score salah dalam mengidentifikasikan dua dari lima puluh laporan keuangan fraudulent sebagai non-fraudulent, dengan nilai $\mathrm{F}$ lebih kecil dari satu, dan tiga laporan keuangan non-fraudulent sebagai fraudulent. Dengan demikian, secara keseluruhan model F-Score memiliki tingkat akurasi sebesar sembilan puluh lima persen, lebih baik dibandingkan dengan model Beneish M-Score.

Tabel 2

Variance Inflation Factor

\begin{tabular}{|l|rllr|}
\hline & \multicolumn{2}{r|}{ VIF } & VIF \\
AQI & 1.540 & \% Soft Assets & 3.987 \\
DEPI & 1.830 & Ch_CS & 2.393 \\
DSRI & 1.609 & Ch_Inv & 1.702 \\
GMI & 2.653 & Ch_ROA & 2.126 \\
LVGI & 1.987 & Ch_Rec & 2.351 \\
SGAI & 1.260 & Issuance & 1.468 \\
SGI & 2.088 & RSST Accru & 3.169 \\
TATA & 1.606 & & \\
\hline
\end{tabular}

Pengujian membuktikan bahwa model Beneish M-Score dan model F-Score efektif dalam mendeteksi kecurangan laporan keuangan. Dengan demikian, $H_{3}$ dan $H_{4}$ dapat diterima.

Tabel 3

Akurasi Model Beneish M-Score dan Model F-Score

\begin{tabular}{|c|c|c|c|c|}
\hline & & Fraudulent & $\begin{array}{c}\text { Non } \\
\text { Fraudulent }\end{array}$ & \\
\hline \multirow{3}{*}{ Beneish M-Score } & Ketepatan & 50 & 36 & 86 \\
\hline & Jumlah Sampel & 50 & 50 & 100 \\
\hline & Akurasi & $100 \%$ & $72 \%$ & $86 \%$ \\
\hline \multirow{3}{*}{ F-Score } & Ketepatan & 48 & 47 & 95 \\
\hline & Jumlah Sampel & 50 & 50 & 100 \\
\hline & Akurasi & $96 \%$ & $94 \%$ & $95 \%$ \\
\hline
\end{tabular}




\section{Diskusi}

Secara parsial, hubungan positif nan signifikan antara variabel days sales receivable index, sales growth index, total accruals to total assets, asset quality index, RSST accruals, changes in receivables, changes in inventories, dan percentages of soft assets terhadap kecurangan laporan keuangan berkaitan dengan teori the fraud diamond - opportunity (Wolfe dan Hermanson, 2004). Manajemen memanfaatkan fleksibilitas general accepted accounting principles untuk melakukan praktik manajemen laba, khususnya atas akun-akun yang berbasis akrual. Sebagai contoh, penggelembungan nilai penjualan dengan membuat penjualan dan debitur fiktif dan penggelembungan nilai aset dengan mengubah kebijakan akuntansi.

Sedangkan hubungan positif nan signifikan antara variabel gross margin index dan leverage index terhadap kecurangan laporan keuangan berkaitan dengan teori the fraud diamond pressure (Wolfe dan Hermanson, 2004). Peningkatan gross margin index merupakan sinyal negatif sebab menunjukkan bahwa laba kotor perusahaan mengalami penurunan. Tekanan untuk memenuhi ekspektasi pemegang saham mendorong manajemen untuk memanipulasi laporan keuangan. Sedangkan peningkatan pada leverage index menunjukkan peningkatan proporsi beban perusahaan. Manajemen laba kerap dilakukan pada saat terjadi peningkatan liabilitas demi memenuhi syarat-syarat yang terkandung dalam debt covenent contract.

Secara simultan, variabel-variabel yang terkandung dalam model Beneish M-Score dan model FScore memiliki hubungan positif nan signifikan terhadap kecurangan laporan keuangan. Ini menunjukkan bahwa semakin besar nilai $\mathrm{M}$ dan nilai $\mathrm{F}$ dari suatu laporan keuangan, maka semakin besar pula kemungkinan laporan keuangan tersebut mengandung kecurangan.

Kedua model juga telah terbukti efektif dalam mendeteksi kecurangan laporan keuangan. Namun model Beneish M-Score gagal dalam mendeteksi kecurangan atas laporan keuangan yang tidak memiliki seluruh data yang dibutuhkan untuk melakukan perhitungan nilai M Beneish. Sebagai contoh, perusahaan jasa tidak memiliki akun persediaan. Laporan keuangan perusahaan jasa yang mengandung kecurangan memiliki nilai $\mathrm{M}$ Beneish lebih kecil dari -2,22. Kedua model juga gagal dalam mendeteksi kecurangan yang terkandung dalam disclosure. Ini dikarenakan kedua model memiliki ketergantungan tinggi atas data keuangan sehingga kesalahan saji material bersifat kualitatif yang terkandung dalam disclosures tidak dapat terdeteksi.

\section{KESIMPULAN DAN SARAN Penutup}

Model Beneish $M$-Score dan model F-Score terbukti efektif dalam mendeteksi kecurangan laporan keuangan yang terjadi di era modern. Namun kedua model memiliki beberapa kelemahan, antara lain cenderung understatement jika laporan keuangan tidak memiliki seluruh data yang dibutuhkan untuk menghitung nilai $\mathrm{M}$ Beneish dan nilai $\mathrm{F}$, dan tidak dapat mendeteksi salah saji material yang terkandung di dalam disclosures. Meskipun demikian pengguna laporan keuangan tetap dapat mengidentifikasi red flag dengan melihat tren pergerakan nila M Beneish dan nilai F. Hubungan positif nan signifikan antara variabel-variabel dalam model Beneish MScore dan model F-Score dengan kecurangan laporan keuangan menggambarkan bahwa nilai M Beneish dan nilai $\mathrm{F}$ cenderung meningkat pada periode kecurangan. Dengan demikian, jika nilai $\mathrm{M}$ Beneish dan nilai $\mathrm{F}$ mengalami tren peningkatan, meskipun tidak lebih besar dari -2,22 atau 1, maka laporan keuangan tersebut patut diduga mengandung salah saji material.

Keterbatasan dari penelitian ini adalah (1) Sampel yang digunakan adalah laporan keuangan yang disajikan sesuai dengan Generally Accepted Accounting Principles sehingga relevansi 
model jika diaplikasikan di negara yang mengadopsi International Financial Reporting Standards belum diketahui dan (2) Sampel dipilih secara ketat sehingga mendiskriminasi datadata yang tidak memenuhi kriteria pemilihan sampel.

Oleh karena itu, disarankan agar peneliti selanjutnya dapat melakukan pengujian model di negara yang mengadopsi sistem akuntansi International Financial Reporting Standards untuk menguji relevansi kedua model. Selain itu, jumlah sampel juga dapat diperbanyak untuk menambah variasi data. Direkomendasikan agar model dapat diuji secara empiris dengan menggunakan populasi. Dan terakhir, model Beneish M-Score dan model F-Score, model yang memiliki ketergantungan tinggi atas data keuangan, dapat diujikan secara bersamaan dengan pendekatan non-keuangan, seperti text mining, agar sebuah model baru dengan tingkat akurasi yang lebih baik dapat diciptakan. Dengan demikian, permasalahan asimetri informasi diharapkan dapat dieliminasi secara sepenuhnya.

\section{REFERENSI}

Alpeyev, P. dan Amano, T. (2015, 20 Juli) "Toshiba to restate at least 152 billion Yen of past profits". Bloomberg. (Retrieved from: https://www.bloomberg.com/news/articles/2015-0720/toshiba-to-restate-152-billion-yen-of-past-profits-after-probe).

Aris, N. A., Arif, S.M.M., Othman, R., dan Zain, M. M. (2015) "Fraudulent financial statement detection using statistical techniques: The case of small medium automotive enterprise". Journal of Applied Business Research 31(4): 1469.

Association of Certified Fraud Examiner. (2016) Report to The Nations on Occupational Fraud and Abuse. (Retrieved from: https://www.acfe.com/rttn2016/docs/2016-report-to-thenations.pdf)

Balachandran, S.V. (2009, Januari 7) "The Satyam scandal". Forbes. (Retrieved from: https://www.forbes.com/2009/01/07/satyam-raju-governance-opedcx_sb_0107balachandran.html\#6f199f33044c).

Beneish, M.D. (1999) “The detection of earnings manipulation”. Financial Analysts Journal 24 $-36$.

Bhavani, G. dan Amponsah, C.T. (2017) "M-Score and Z-Score for detection of accounting fraud". Accountancy Business and the Public Interest 68 - 86. (Retrieved from: http://visar.csustan.edu/aaba/BhavaniAmponsah2017.pdf).

Bloomberg (2001, Desember 17) "The fall of Enron". Bloomberg. (Retrieved from: https://www.bloomberg.com/news/articles/2001-12-16/the-fall-of-enron).

Cecchini, M., Aytug, H., Koehler, G.J., dan Pathak, P. (2010) "Making words work: Using financial text as a predictor of financial events". Decision Support Systems 50: $164-175$.

Dechow, P.M., Ge, W., Larson, C.R., dan Sloan, R.G. (2011) "Predicting material accounting misstatements". Contemporary Accounting 28 (1): 17-82.

Detik Finance (2009, September 9) "Usai manipulasi keuangan". Waskita Karya segera direstrukturisasi. Detik Finance. (Retrieved from: https://finance.detik.com/beritaekonomi-bisnis/1200038/usai-manipulasi-keuangan-waskita-karya-segera-direstukturisasi).

Hery, S.E. (2016) Auditing dan Asurans. Jakarta: PT Grasindo.

Higson, A. (2003) Corporate financial reporting: theory and practice. London: Sage Publications.

Jensen, M. C. dan Meckling, W. H. (1976) "Theory of the firm: Managerial behavior, agency costs and ownership structure". Journal of Financial Economics 3(4): 305-360. doi:10.1016/0304-405X(76)90026-X.

Rahadiana, R. (2009, Agustus 28) "Tiga direksi Waskita dinonaktifkan”. Tempo. (Retrieved from: https://bisnis.tempo.co/read/194968/tiga-direksi-waskita-dinonaktifkan). 
Repousis, S. (2016) "Using Beneish model to detect corporate financial statement fraud in Greece". Journal of Financial Crime 23 (4): 1063 - 1073.

Scott, W.R. (2015) Financial accounting theory ( $7^{\text {th }}$ ed.). United States: Pearson Education.

Singleton, T.W. dan Singleton, A.J. (2010) Fraud auditing and forensic accounting ( $4^{\text {th }}$ ed.). New Jersey: John Wiley \& Sons.

Spence, M. (1973) "Job market signaling”. The Quarterly Journal of Economics 87 (3): 355-374.

Tarjo dan Herawati, N. (2015) "Application of Beneish M-Score Models and Data Mining to detect financial fraud”. Social and Behavioral Sciences 211: 924 - 930.

Tran, M. (2002, Agustus 9) "WorldCom accounting scandal". Guardian. (Retrieved from: https://www.theguardian.com/business/2002/aug/09/corporatefraud.worldcom2).

Tuanakotta, T.M. (2013) Mendeteksi manipulasi laporan keuangan. Jakarta: Salemba Empat.

Wolfe, D. dan Hermanson, D. (2004) "The fraud diamond: considering the four elements of fraud". The CPA Journal 74 (2): 38-42. 